Ex-ante economic evaluation of agricultural research in New Zealand - a conceptual framework

Wei Yang ${ }^{\text {ab }}$ and Sue Zydenbos ${ }^{\mathrm{a}}$

${ }^{a}$ AgResearch Limited Lincoln Research Centre, Farm System and Environment, Lincoln, New Zealand; ${ }^{b}$ Faculty of Agribusiness and Commerce, Lincoln University, Lincoln, New Zealand wei.yang@lincoln.ac.nz; Lincoln University, 1365 Springs Road, Lincoln 7674, New Zealand 


\title{
Ex-ante economic evaluation of agricultural research in New Zealand-a conceptual framework
}

\author{
Returns to agricultural research are of significant interest to funding bodies and \\ research administrators. Ex-ante economic analyses have increasingly formed part of \\ decision-making process of allocating funds to agricultural research proposals. ex-ante \\ analyses are required to present economic rankings to governments and funding \\ agencies for comparing the impact of agricultural research proposals. Although \\ important, there is no consistent guidelines for scientists and practitioners to follow in \\ New Zealand. The study aims to develop a conceptual framework for agricultural \\ research projects in understanding, assessing, planning and managing relevant issues in \\ ex-ante evaluation of impacts.
}

Keywords: agricultural research; ex-ante analysis; cost-benefit analysis; consistency

\section{Introduction}

Agriculture is a vital contributor to the New Zealand (NZ) economy, and thus returns to agricultural research are of significant interest to funding bodies and research administrators. In NZ, the investment in research and development (R\&D), measured as a proportion of gross domestic product (GDP), is about $1.25 \%$ and predominantly from the public sector (StatsNZ 2017). Although this number has significantly increased from below $1 \%$ since the late 1990 s, it continues to be well below the OECD average of 2.4\% (StatsNZ 2017). As the government budgets tighten, there has been a growing demand for reliable impact analyses to appropriately measure the investment returns over different research projects, whereby consideration is given to the economic, social, and environmental dimensions (Helming et al. 2011). Impact assessments of agricultural research can be classified into a) ex-ante analyses that are undertaken before the project is started, and b) ex-post analyses that are undertaken after the completion of the project (Evenson 2001). Weißhuhn et al. (2017) consider ex-ante impact assessment to be more instructive than ex-post assessment because it can directly guide the design of research towards maximising beneficial impacts. Although impacts of 
R\&D activities create value that often go far beyond what can be captured in financial terms, in most cases in NZ, ex-ante analyses are required to present economic rankings to governments and funding agencies for comparing the impact of agricultural research proposals (Mullen J. D. et al. 2008). To a great extent, the ex-ante economic analyses have increasingly formed part of decision-making process of allocating $R \& D$ funds to research proposals (Driesen 2006).

Cost-benefit analysis (CBA) has been the most widely used method for scientists, analysts and practitioners to present returns to proposed projects by evaluating the associated costs and benefits in NZ (the Treasury NZ 2017). The Treasury NZ has developed a CBA tool, namely CBAx, to ensure that robust value for monetary assessment is applied to investment and budget decisions (the Treasury NZ 2017). Due to the "easy-to-follow" characteristics, the CBAx is expected to use to present economic values of $\mathrm{R} \& \mathrm{D}$ activities. However, CBAs of agricultural research present challenges that other types of impact assessments do not, such as dynamic biological environments, complex farming systems, aggregation issues and difficulties in identifying appropriate counterfactuals (Norton 2015). What is provided by the CBAx toolbox could only support rigorous transparent evidencebased CBAs of budget initiatives (the Treasury NZ 2017). It is therefore not possible to use the CBAx toolbox to measure returns to agricultural research in terms of costs and benefits.

Literature on the evaluation of agricultural research and innovation mostly focuses on ex-post impact assessments (Weißhuhn et al. 2017). Hence, the empirical results of the expost economic analyses provide a rich source of data that contribute to the most studied area in literature of evaluating returns to different $R \& D$ activities in agriculture (e.g. Dooley et al. 1998; Evenson 2001; Shackell et al. 2003; Mullen J. D. et al. 2008; Schut et al. 2015; Tozer et al. 2015; Fowler et al. 2016). Although there are some studies that touched on the estimation processes and methods, those also tended to focus on ex-post economic 
evaluations (e.g. Evenson 2001). What few published ex-ante studies were designed for a specific project, and thus the evaluation process of costs and beneficiaries were hard to follow and replicate (e.g. Demont et al. 2009). A broad discussion about the importance of ex-ante impact assessments occurred in the European Union, where the European Union Sustainable Development Strategy explicitly reinforced the importance of using a highquality ex-ante impact assessment as a tool to improve policy making of land use change (Council of the European Union 2006). However, in general, due to time constraints and lack of relevant data, researchers and practitioners have to conduct ex-ante economic evaluations based on bold guessing or simple assumptions of both costs and beneficiaries (Marshall and Brennan 2001). In addition, those that are difficult to measure in monetary unit, very often, are ignored or excluded in the economic evaluations. This is why the ex-ante impact analyses of agricultural projects, especially ex-ante CBAs, are not entirely convincing to scientists and the public (Driesen 2006).

So far, there has been no consistent guidelines or 'best practices' of ex-ante economic analyses of agricultural research and innovation for scientists and practitioners to follow in NZ. Notably, if the ex-ante analysis was not properly designed, conducted and documented, the monetary assessments would be more like false advertising rather than accountable evaluations (Ross 1999). By critically reviewing relevant studies, we aim to investigate the issues that need to be considered in ex-ante impact analyses of agricultural research in NZ, and to develop a conceptual framework that can help improve consistency in design, execution processes, and evaluation methods of ex-ante economic analysis.

\section{Questions to consider in ex-ante economic analyses}

In NZ, ex-ante impact analyses are believed to help with the difficult decision-making in the allocation of limited resources for funding agencies. Till now, a large number of ex-ante impact analyses have been conducted across different agricultural sectors. However, most of 
those are 'in-house' works that are included in either research proposals or project reports and could only be accessed through internal channels of research institutes and governments. It is therefore difficult to measure the consistency, accountability and credibility of these ex-ante analyses.

Literature on either ex-post or ex-ante economic evaluation of agricultural research has been very thin in NZ, where only a few studies estimated returns to ex-post projects in terms of productivity growth at a macro level (Scobie and Eveleens 1987; Mullen John D et al. 2006; Mullen J. D. et al. 2008). In addition to the above studies, the most recent discussion focusing on design, estimation and implementation of ex-ante economic analyses was traced back to a workshop in 1996, namely 'economic evaluation of agricultural research in Australia and New Zealand' (Brennan and Davis 1996). A series of workshop papers reviewed the past of research and science systems and the performance of available cases of CBA in Australia and NZ. These papers also addressed the unresolved issues, such as lacking knowledge of adoption rates, disconnection and disagreement between scientists and economists, and difficulties in estimating benefits as a results of improved quality attributes (Brennan and Davis 1996). So far, some of those issues have not been solved.

\section{Formation of impact pathway}

Understanding the impact pathway of an ex-ante economic analysis is what has been usually neglected in the process of designing an agricultural research plan. Very often, scientists consider about research impacts (or involvement of analysts in evaluating the impacts) after completing the science research proposal. The main reasons of ignoring this issue are that scientists mostly focus on the science components and they oversimplify the role of impact pathway (Brennan and Davis 1996). This, however, could lead to either the omission of important components of an economic analysis or leaving limited time for analysts to obtain information about the real impact. However, if the formation of impact pathway was not 
appropriately considered, the following steps of economic evaluation of the research plan could not be implemented in a systematic and consistent way.

A classic view of ex-ante economic analysis is a linear process where resources, such as time, people, and capital investment, are employed to achieve some intended research outputs, with a given probability of success (Delanghe and Muldur 2007). This process is depicted in Figure 1.

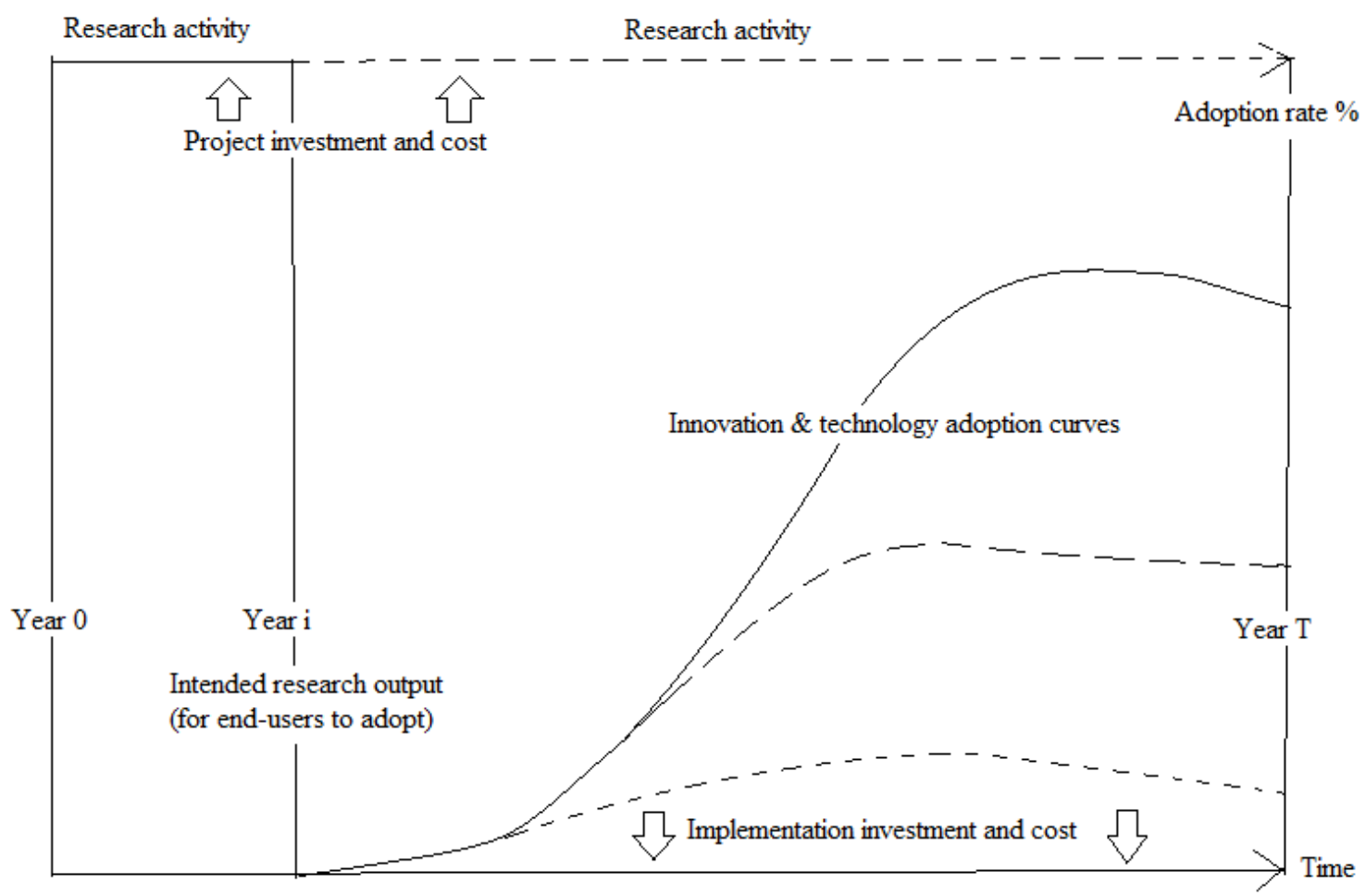

Figure 1. Impact pathway of agricultural research activity

The impact pathway is visualised from the start of research activity in 'Year 0' to 'Year $i$ '. After that, if the intended research outputs can indeed be generated, it is expected to be adopted by the end users (e.g. farmers) through a specific adoption curve till 'Year $T$ ', which could be either a short-term time frame (e.g. 3 years and 5 years) or a long-term time frame (e.g. 10 years and 20 years). It is often assumed that adoption of the end-product begins immediately at the end of the research project period, i.e. Year $i$. End-users' adoption usually follows a sigmoidal curve, depicted as the upper adoption curve in Figure 1, where 
adoption begins slowly at the beginning, gradually accelerating, and then decelerating till it reaches the ceiling. However, the adoption curve could be in various shapes, considering different characteristics of the end-outputs, end-users, and the associated implementation investment and cost. And thus, the adoption rate could also follow the two lower curves in Figure 1.

Although the impact pathway of agricultural innovation may be much more complex than what is shown in the linear process in Figure 1, it is still useful to map an overview of expectations for the ex-ante economic analysis. It is also a good starting point for different actors, including scientists, analysts, and stakeholders to be on board and set priorities in different stages (Sayer and Campbell 2001). During this process, specifically, they can start scoping the analysis framework in terms of models and parameters to use, consider what kinds of impacts could be monetarised, and understand the targeted end-users for further prediction of their adoption patterns (Joly et al. 2016).

\section{What, where, who}

After scoping the impact pathway, it comes to consider three main questions in exante economic analysis, that is to identify a) where the impacts are, b) who are affected, and c) what impacts to be included. Thus, the core of ex-ante assessment of investment is to identify the appropriate costs and benefits, measure the per unit effects of the agricultural research innovations, and aggregate the effects over the target population and time. However, impacts could occur at the field, farm, regional, national, or even international level, which can result in multidimensional impact on farm profitability, the environment, food security and food safety, and poverty reduction. Therefore, mapping the answers to the above questions needs a systems approach that links potential impacts and different stakeholders together (Perdicoúlis, A., 2016). Otherwise, the ex-ante analysis could easily fall into the 
pitfall of targeting distinct impact or specified population.

Regarding 'where and who', as economic evaluations are often considered at the project level, scientists and analysts tend to concentrate on the direct impact of agricultural activities and sometimes neglect spillover effects that might be picked up by other industries and the public. For example, the genetic improvement for heavier sheep will result in new requirements for farmers regarding farming practices such as management of pasture supply, animal welfare, and staff training. This could also place challenges for transportation and processing. In this case, the estimation of costs and benefits should not be only focusing on the innovation spilled from lab to farm, but also tracking further spillover impacts on other levels.

In addition, a typical ex-ante economic analysis tends to estimate/aggregate the economic values of a science innovation from the so called the 'benchmark' sites, where certain biological characteristics and responses are obtained and regarded as being representative to a broader context (Bouman et al., 1999). It may be true that, if relevant biological and physical information is controlled, the identification of benchmark results could be aggregated to a higher-level impact. However, although important, biophysical characteristics are not the only factors for the applicability and adoption of science innovation, for instance, innovation efforts differ between farm systems (Läpple et al. 2015). In addition, the uptake or adoption of innovations is highly dependent on the complex decision-making process of farmers (Läpple et al. 2015).

\section{Adoption of innovations}

One of the most difficult factors to estimate in ex-ante economic impact analyses is the adoption rate of science innovations, such as the adoption of technologies and intended practice changes (Brennan and Davis 1996). As was mentioned previously, isolating the impact of science innovation is a complex process as the pure science impact, e.g. biological 
impact, can only partly affect end users' choice behaviours. Thus, to properly estimate/predict the adoption rate of a specific innovation, it is important to firstly understand what and how different factors affect farmers' adoption or non-adoption of science innovations.

\section{What to maximise?}

In terms of what drive farmers' adoption of science innovations, the adoption literature has provided a list of key determinants, including farmer and farm characteristics, farmer's ability and motivation, farmer's attitude to and perception of the innovation, and knowledge diffusion (e.g. Pannell et al. 2006; Posthumus et al. 2010; Fernandez 2017). In addition to providing useful factors for one to consider in the ex-ante evaluation, these studies also highlight that farmers are motivated to adopt by a mix of purposes, rather than just driven by production or profitability. Hence, the assumption of production maximisation or profit maximisation may lead to an inaccurate prediction of adoption rate. For example, some studies find out that older farmers tend not to adopt new technologies, which could be due to their choice of life style (Rolfe and Gregg 2015). In this case, the assumption of utility maximisation might be more appropriate to capture farmers' choice decision of innovation adoption, where different farmer groups could be assigned a specific weight according to a key characteristic, for instance early adopters and later adopters (Läpple and Rensburg 2011).

Thus, the $i^{\text {th }}$ farmer is willing to adopt depending on utility $\left(U_{i}\right)$ maximization when the probability of adoption can be denoted as $\operatorname{Pr}\left(W T A_{i}=1\right)=\operatorname{Pr}\left(U_{1 i}-U_{0 i} \geq 0\right)=\operatorname{Pr}\left(W T A_{i}^{*} \geq 0\right)$, where $W T A_{i}^{*}=U_{1 i}-U_{0 i}$ represents the utility difference associated with observed indicator 1 (to adopt) and 0 (not to adopt). Based on a traditional choice model, $W T A_{i}^{*}$ could be specified as a function of the determinants that may affect farmers' decision-making, $W T A_{i}^{*}=f(X, w, \varepsilon)$, where $X$ represents the key determinants of the farmer's adoption; $w$ is 
the weight assigned to any determinants; and $\varepsilon$ is the error term. Furthermore, in addition to looking at adoption or non-adoption, some studies attempt to understand how the above factors affect the intensity of adoption, which provide a good way of estimating the adoption rate taking into account the heterogeneous farmer and farm characteristics(Arslan et al. 2014; Brown and Roper 2017). Notably, when the intensity of adoption is mapped over time, the adoption rates could be tracked (Yang et al. 2019).

\section{Spillover effects}

The existence of spillover effects could lead to indirect impacts that need to be addressed in the economic evaluation of ex-ante analyses of agricultural research. One key source of the effects is the spatial or network spillovers from geographically close farmers or socially close farmers (Akerlof 1997; Yang and Sharp 2017). From a cost-benefit perspective, the information spillovers could help farmers reduce the fixed cost of learning about the intended innovations by learning from the geographically-close and socially-close farmers. Then, the willingness to adopt function should consider the spatial or social network effects and shown as $W T A_{i}^{*}=f(X, S, w, r, \varepsilon)$, where $S$ denotes the unobserved spatial or social effects existing between farmer $i$ and farmers located in close proximity.

There is another spillover effect that has rarely been considered coming from the market, and this about the estimation of improved quality attributes was one of the unsolved issues in the Australia-NZ CBA workshop (Brennan and Davis 1996). Significantly, this effect has increasingly become an important driver for farmers' adoption of science innovations in NZ. Fortunately, some recent studies have pointed out a promising direction toward how to use this unmeasurable effect from the market. For instance, Yang and Renwick (2019) and Dolgopolova and Teuber (2018) have estimated consumer willingness to pay price premium associated with types of good attributes, such as environmentally-friendly, 
good animal welfare, and tractability, and all these could be seen as a monetarised measurement of the market spillovers. In addtion, there is an increasing interest in linking the market estimation to farming practice and farm system changes, and a few studies, for instance Olynk et al. (2010) and White and Brady (2014) have started to combine the market analyses results with farm system modelling. Given the increasing demand for high quality attributes and environmental pressures, many agricultural studies in NZ have to take into account the monetarised market spillover in the ex-ante economic analysis, which adding an external factor $e$ (e.g. denoting market spillover) to re-define the farmers' adoption function as $W T A_{i}^{*}=f(X, S, w, e, \varepsilon)$. It is noted the external factor is not inclusive to market spillover but might include the impact of government regulations which could be monetarised as a cost to be added in the economic analysis.

\section{ADOPT model}

Although we have identified factors to be considered in the estimation of adoption rates, the process still requires a specific mixed expertise including economics, mathematics and econometrics. An alternative way to predict adoption rates is to use a prediction tool named the adopt and diffusion outcome prediction tool (ADOPT) that is recently developed by the CSIRO (Kuehne et al. 2017). Based on profit maximisation at farm level, the ADOPT model could be used to predict adoption rates of targeted end-user groups, and the possible peak extent of adoption over a time period. This tool has been tested by using several cases and data from Australia where the results show consistency and accuracy of the predicted adoption rates compared to the real follow-up adoption rates (Kuehne et al. 2017).

However, to use the tool, pilot studies (e.g. interviews or focus group) may be needed to get the information of the targeted end users, including their demographic characteristics and attitudes toward innovation, and the information about the specific innovation, for 
example whether it is related to environmental protection. Thus, the tool could be used at the early stage when planning the impact pathway with the help of economists and social scientists.

\section{The link between ex-post and ex-ante analysis}

To validate the proposed benefits of ex-ante studies, some funders usually require ex-post analyses to evaluate the real values of implementing one project by the end of the project. This partly explains the difference in numbers of ex-ante and ex-post publications, where scientists tend to publish their scientific findings toward the end of the project, and intuitively, the associated economic evaluations have then been published in academic journals (Maredia, Byerlee, \& Anderson, 2000). Although this is the commonly seen linkage between the ex-ante and ex-post economic analyses, the comparison of the two evaluations have rarely been open for the public to view. However, given that the literature of ex-post impact studies has included the economic evaluations, results of the studies could be formed as a database and further used in the following ex-ante impact analyses. For example, it would be useful for analysts to form a database with relevant information of ex-post impact studies in a research institute. When it comes to assessing similar types of innovations or targeted end-users, the results from the ex-post studies could be the most powerful source of cost, benefits and adoption rates. In addition, quantitative review methods, for instance metaanalysis, could be used to summarise relevant results drawn from 'the database' so that the statistical estimates (point estimates or confidence intervals) could be utilised in quantifying the economic impacts of ex-ante studies.

\section{The conceptual framework of ex-ante economic analysis}

Based on the questions discussed in the above sections, a conceptual framework for evaluating ex-ante economic impact assessment of agricultural research will be presented in 
this section. Figure 2 shows the structure of the framework from the start of planning the impact pathway all the way to the final stage of validation. 


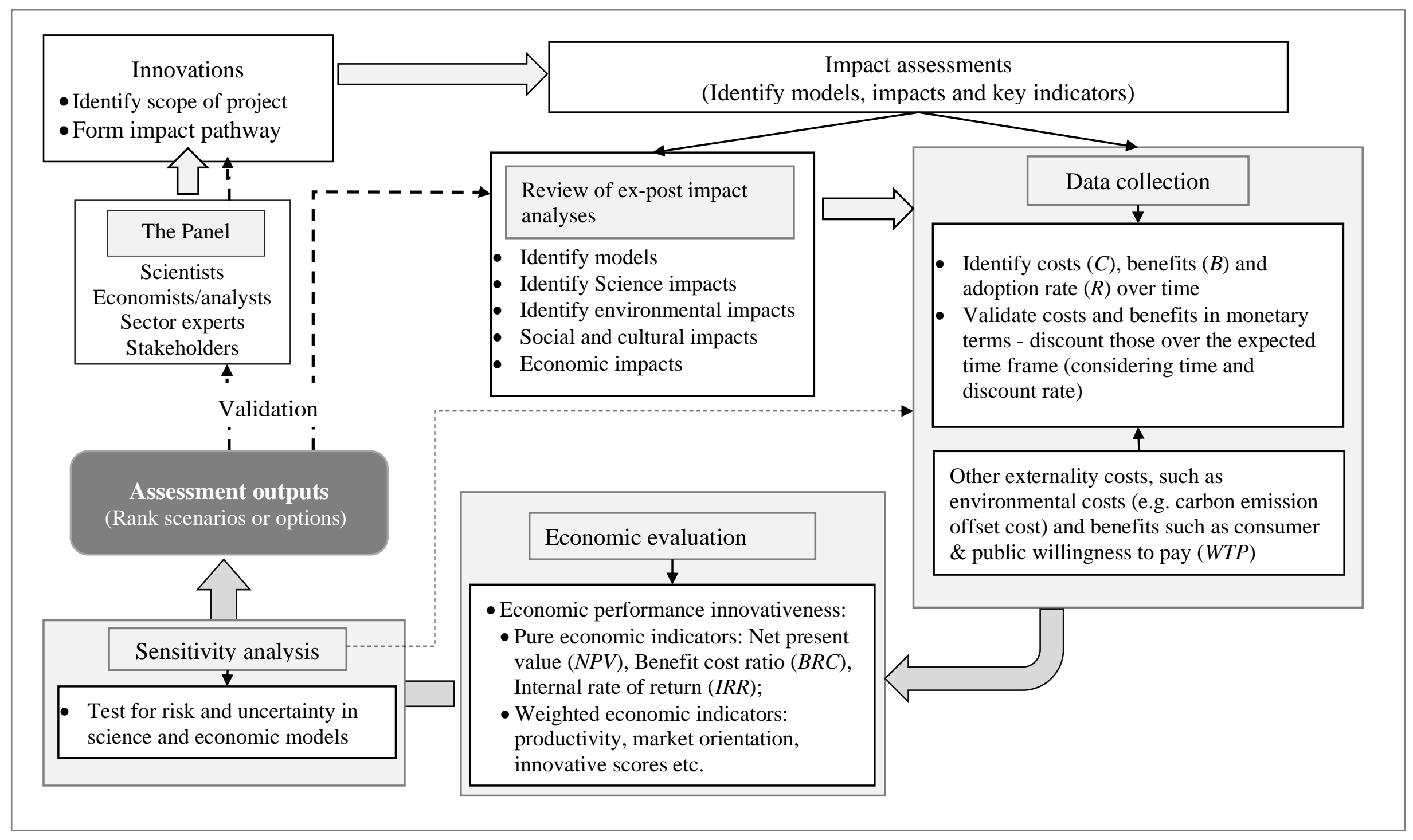

Figure 2. Conceptual framework of ex-ante economic analyses 
1. To form the impact path way

Starting from the left corner of the flow chart, an ex-ante economic impact assessment of an agricultural research begins with the idea of the science innovation, which is mostly about the science impact of the research project. However, to show the funders about the potential economic impact, it is important to have relevant actors on board to identify the scope of the project, form the impact pathway, and set priorities. The planning stage could involve a range of people with different perspectives and skill sets. Scientists, analysts/ economists, modellers, sector experts and relevant stakeholders could all work together and initiative the template of ex-ante impact evaluation. During the formation of the impact pathway, saying a typical linear impact pathway, the panel can work out the expected short-term and long-term framework, map the impact along the value chain from farm to market, and identify the end-users.

2. To determine impacts and key indicators and collect data

After forming the impact pathway, the analyst could start review relevant expost economic impact analyses to explore what kinds of impacts and associated economic values have been evaluated by the previous studies. This exploration may include all the published papers and data as well as the 'grey literature' most of which are internal reports and data archives. Reviewing the relevant ex-post analyses provides a good understanding of the impacts of similar research projects, helps build a source of information about cost, benefit and adoption rate, and feed the information of previous ex-post studies into current or future ex-ante analyses. The connection also provides an opportunity for the ex-ante assessment to validate the evaluation with the comparison to the previous ex-post studies.

As is proposed by (Joly et al. 2016), the future of research impact analyses will depend on the capacity to improve estimation methods and gather quality information 
(which also takes into account non-economic impacts) and the sharing of good practices. Therefore, after reviewing the previous ex-post impact studies, the panel could determine key impacts of the innovations from different perspectives, such as science, economic, environmental, and social and cultural impact. Meanwhile, the panel could decide on which models to identify the impacts (e.g. the ADOPT model to predict adoption rates, FARMAX to model farm level financial outputs, and OVERSEER to estimate nitrate leaching (Bryant et al., 2010, Wheeler et al., 2006), and to identify associated indicators for each impact. This could further help locate relevant information and data to quantify or monetarise the impact. In addition, we need to consider the indicators that have been usually ignored previously. For example, the market signals regarding consumers' preferences and willingness to pay and government regulations regarding agricultural production need to be monetarised and considered in evaluating the targeted impacts. Lastly, all the quantified impacts should be adjusted in the proposed time frame, and accordingly, the analyst has to adjust the evaluation by using appropriate discount rates.

3. Economic evaluation and sensitivity analysis

Under the perfect scenario, all the costs and benefits can be adjusted in monetarised terms over time, and the ex-ante economic impacts could be presented using the pure economic indicators, such as net present value, benefit cost ratio, and internal rate of return. However, very often, some of the impacts could not be easily monetarised and so other indicators may be useful to be presented, such as productivity, market orientation and other innovative scores (e.g. (Läpple et al. 2016). Although the non-monetary measurements might make the impact analyses of the research proposals less economically attractive to funding agencies, it is much more convincing than false economic estimations. 
Another important step that has been forgot is to test for the sensitivity of key parameters of the ex-ante economic analysis. A sensitivity analysis ensures the robustness of the ex-ante economic evaluation, with potential risks and uncertainties considered. Key parameters to be tested include variables and parameters in the science perspective, for example, we might consider testing for the volatility of pasture growth rate due to climatic issues if the science innovation is to maximising pasture growth in a farm system. In addition, the sensitivity of some parameters estimated in the economic analysis need to be tested, and these may include the adoption rate, discount rate, and some key external factors (e.g. consumer willingness to pay and carbon emission cost). The sensitivity analysis could help the funders to understand the robustness of the exante economic impact analysis, presented as a range of economic values of the proposed impacts of the research.

4. Validation of ex-ante economic evaluation

When the sensitivity analysis is finished, economic outcomes of different modelling scenarios could be ranked according. Usually this is regarded as the last step of ex-ante economic analysis of an agricultural research. However, to deliver the final results to the funders, scientists and analysts need to connect and compare the estimated results with the previous ex-post studies identified in Step 2. This is an important step to reflect the consistency of the estimated result with the ex-post studies, results of which have been commonly based on observed economic impacts. In addition to comparing to ex-post studies, the results should also be evaluated and validated by the panel of the research project, where relevant stakeholders (e.g. sector experts) could provide thoughts on the evaluations. Thus, appropriate modifications and revisions could be made based on the validation. 


\section{Conclusion}

Ex-ante economic impact has increasingly become an important part in determining the success of a proposal of agricultural research in NZ. However, the NZ scientists are either lack of or too busy to use the appropriate skills to provide a proper ex-ante economic impact analysis. It is therefore important to construct a framework that could be used in a consistent way to guide the scientists or practitioners to conduct an ex-ante economic impact analysis. By reviewing relevant literature of economic impact analysis, this study attempted to raise some importance questions that need to be considered in the practice of ex-ante impact analyses and proposed a conceptual framework for future ex-ante impact analyses. We specifically highlighted the importance to form the impact pathway, to identify what, where the impacts are and who could be affected in conducting the science innovation, to consider potential spillover effects, and to choose an appropriate model for the prediction of adoption rates.

Adopting the conceptual model could help avoid possible 'institutional errors', for instance change of line manager, to ensure the consistency of design, execution and implementation of ex-ante economic impact analyses. Significantly, in the conceptual model, we highlighted the importance of including relevant stakeholders from the beginning of impact pathway formation all the way to the validation of final estimation results. All these can contribute by supporting decisions on the allocation of resources, helping achieve a cultural shift in the organisations, and helping to win or maintain funds (Horton and Mackay 2003). 


\section{Acknowledgements}

This research was funded by AgResearch Limited (Strategic Science Investment Fund A22715).

\section{Reference:}

Akerlof GA. 1997. Social distance and social decisions. Econometrica: Journal of the Econometric Society.1005-1027.

Arslan A, McCarthy N, Lipper L, Asfaw S, Cattaneo A. 2014. Adoption and intensity of adoption of conservation farming practices in Zambia. Agriculture, Ecosystems \& Environment. 187:72-86.

Bouman, B. A., Jansen, H. G., Schipper, R. A., Nieuwenhuyse, A., Hengsdijk, H., \& Bouma, J. (1999). A framework for integrated biophysical and economic land use analysis at different scales. Agriculture, ecosystems \& environment, 75(1-2), 55-73.

Bryant, JR, Ogle, G, Marshall, PR, Glassey, CB, Lancaster, JAS, Garcia, SC, Holmes and CW, 2010. Description and evaluation of the Farmax Dairy Pro decision support model. New Zealand Journal of Agricultural Research, 53(1), 13-28.

Brennan JP, Davis J. 1996. Economic evaluation of agricultural research in Australia and New Zealand. Australian Centre for International Agricultural Research.

Brown P, Roper S. 2017. Innovation and networks in New Zealand farming [Article]. Australian Journal of Agricultural \& Resource Economics. 61(3):422-442.

Delanghe H, Muldur U. 2007. Ex-ante impact assessment of research programmes: The experience of the European Union's 7th Framework Programme. Science and Public Policy. 34(3):169-183.

Demont M, Rodenburg J, Diagne M, Diallo S. 2009. Ex ante impact assessment of herbicide resistant rice in the Sahel. Crop Protection. 28(9):728-736.

Dolgopolova I, Teuber R. 2018. Consumers' Willingness to Pay for Health Benefits in Food Products: A Meta-Analysis. Applied Economic Perspectives and Policy. 40(2):333-352.

Dooley AE, Parker WJ, Rauniyar GP, McCutcheon SN, Morris ST. 1998. Returns to investment in on-farm research: A case study of cover comb technology. New Zealand Journal of Agricultural Research. 41(3):405-414.

Evenson RE. 2001. Chapter 11 Economic impacts of agricultural research and extension. Handbook of Agricultural Economics. Elsevier; p. 573-628.

Fernandez MA. 2017. Adoption of erosion management practices in New Zealand. Land Use Policy. 63:236-245.

Fowler SV, Gourlay AH, Hill R. 2016. Biological control of ragwort in the New Zealand dairy sector: an ex-post economic analysis. New Zealand Journal of Agricultural Research. 59(3):205-215.

Helming K, Diehl K, Kuhlman T, Jansson T, Verburg PH, Bakker M, Perez-Soba M, Jones L, Verkerk PJ, Tabbush P. 2011. Ex ante impact assessment of policies affecting land use, Part B: application of the analytical framework. Ecology and Society. 16(1). 
Horton D, Mackay R. 2003. Using evaluation to enhance institutional learning and change: recent experiences with agricultural research and development. Agricultural Systems. 78(2):127-142.

Joly P-B, Colinet L, Gaunand A, Lemarié S, Matt M. 2016. Agricultural research impact assessment.

Kuehne G, Llewellyn R, Pannell DJ, Wilkinson R, Dolling P, Ouzman J, Ewing M. 2017. Predicting farmer uptake of new agricultural practices: A tool for research, extension and policy. Agricultural Systems. 156:115-125.

Läpple D, Rensburg TV. 2011. Adoption of organic farming: Are there differences between early and late adoption? Ecological Economics. 70(7):1406-1414.

Läpple D, Renwick A, Cullinan J, Thorne F. 2016. What drives innovation in the agricultural sector? A spatial analysis of knowledge spillovers. Land Use Policy. 56:238-250.

Läpple D, Renwick A, Thorne F. 2015. Measuring and understanding the drivers of agricultural innovation: Evidence from Ireland. Food Policy. 51:1-8.

Trends in research, productivity growth and competitiveness in agriculture in New Zealand and Australia. 2006 Conference, August 24-25, 2006, Nelson, New Zealand; 2006: New Zealand Agricultural and Resource Economics Society.

Maredia, M. K., Byerlee, D., \& Anderson, J. R. (2000). Ex post evaluation of economic impacts of agricultural research programs: a tour of good practice.

Mullen JD, Scobie GM, Crean J. 2008. Agricultural research: Implications for productivity in New Zealand and Australia. New Zealand Economic Papers. 42(2):191-211.

Evaluating Economic Impacts of Agricultural Research: What Have We learned. Draft Seminar paper, Department of Agricultural and Resource Economics, North Carolina State, University; 2015.

Olynk NJ, Tonsor GT, Wolf CA. 2010. Verifying credence attributes in livestock production. Journal of Agricultural and Applied Economics. 42(3):439-452.

Pannell DJ, Marshall GR, Barr N, Curtis A, Vanclay F, Wilkinson R. 2006. Understanding and promoting adoption of conservation practices by rural landholders. Animal Production Science. 46(11):1407-1424.

Perdicoúlis, A. (2016). Systems thinking and SEA. Impact assessment and project appraisal, 34(2), 176-179.

Posthumus H, Gardebroek C, Ruben R. 2010. From Participation to Adoption: Comparing the Effectiveness of Soil Conservation Programs in the Peruvian Andes. Land Economics. 86(4):645-667.

Rolfe J, Gregg D. 2015. Factors affecting adoption of improved management practices in the pastoral industry in Great Barrier Reef catchments. Journal of Environmental Management. 157:182-193.

Ross K. 1999. Institutional and social influences on R\&D evaluation in agriculture. Australian Journal of Agricultural and Resource Economics. 43(1):115-128.

Schut M, Rodenburg J, Klerkx L, Kayeke J, van Ast A, Bastiaans L. 2015. RAAIS: Rapid Appraisal of Agricultural Innovation Systems (Part II). Integrated analysis of parasitic weed problems in rice in Tanzania. Agricultural Systems. 132:12-24.

Scobie GM, Eveleens WM. 1987. The return to investment in agricultural research in New Zealand: 1926-27 to 1983-84. Economics Research Section, Policy Services, MAFCorp, Ruakura Agriculture Centre.

Shackell GH, Drew KR, Pearse AJT, Amer PR. 2003. A cost-benefit analysis of the value of investment in a wapiti hybridisation research programme and the returns to 
New Zealand venison producers. New Zealand Journal of Agricultural Research. 46(2):133-140.

StatsNZ. 2017. Research and development in New Zealand: 2016. www.stats.govt.nz. Tozer KN, Rennie GM, King WM, Mapp NR, Aalders LT, Bell NL, Wilson DJ, Cameron CA, Greenfield RM. 2015. Pasture renewal on Bay of Plenty and Waikato dairy farms: impacts on pasture performance post-establishment. New Zealand Journal of Agricultural Research. 58(3):241-258.

The Treasury NZ. 2017. CBAx Tool User Guidance. Available at: http://www.treasury.govt.nz/publications/guidance/planning/costbenefitanalysis/cbax (accessed on 12 December 2018).

Weißhuhn P, Helming K, Ferretti J. 2017. Research impact assessment in agricultureA review of approaches and impact areas. Research Evaluation. 27(1):36-42.

Wheeler D, Ledgard S F, Monaghan R M, McDowell R and de Klein C 2006. Overseer development - what it is, what it does. In Implementing Sustainable Nutrient Management Strategies in Agriculture. (Eds. L.D. Currie and J.A. Hanly).

Occasional Report No. 19. Fertilizer and Lime Research Centre, Massey University, Palmerston North, New Zealand. pp231-236.

White RR, Brady M. 2014. Can consumers' willingness to pay incentivize adoption of environmental impact reducing technologies in meat animal production? Food Policy. 49:41-49.

Yang W, Renwick A. Consumer Willingness to Pay Price Premiums for Credence Attributes of Livestock Products - A Meta-Analysis. Journal of Agricultural Economics. 0(0).

Yang W, Sharp B. 2017. Spatial Dependence and Determinants of Dairy Farmers' Adoption of Best Management Practices for Water Protection in New Zealand [journal article]. Environmental Management. 59(4):594-603.

Yang W, Renwick A, Edwards P, Eastwood C 2019. Labour saving or decisionsupport? A joint analysis framework of dairy farmers' adoption intensity of smart technology in NZ. Lincoln University, Lincoln, NZ. 